\title{
Heterotopic Pregnancy and Septic Miscarriage: A Case Report Illustrating Risks of "Medical Shopping", Mostly for Tricky Diagnoses
}

\author{
Frédéric $\mathrm{B}^{1,2}$, Gilles $\mathrm{F}^{1}$, Danah V0 ${ }^{1}$, Noëlie $\mathrm{D}^{3}$ and Leonardo $\mathrm{G}^{1}$ \\ ${ }^{1}$ Department of Obstetrics and Prenatal Medicine, UZ Brussel University Hospital, Belgium \\ ${ }^{2}$ Department of gynecological surgery, Arnaud de Villeneuve Hospital, France \\ ${ }^{3}$ Department of Gynecology, UZ Brussel University Hospital, Belgium
}

Submission: May 09, 2020; Published: June 09, 2020

*Corresponding author: Frédéric Blavier, Department of Obstetrics and Prenatal Medicine, UZ Brussel University Hospital, Belgium and Department of gynecological surgery, Arnaud de Villeneuve Hospital, France

\begin{abstract}
Background: Spontaneous heterotopic pregnancy and septic miscarriage are both rare and, each, associated with potential severe morbidity (shock, potential infertility) and mortality.

Case presentation: A young and spontaneously pregnant woman presented acute abdomen and spotting with an empty uterus, liquid in the Douglas and a right tube mass in ultrasound with positif hCG and moderate inflammation, without fever. During the laparoscopy performed for a suspected ectopic pregnancy, were discovered ascites, and pus in the right fallopian tube. After surgery, we observed a multiple organ failure (ARDS, DIC, kidneys and liver insufficiencies) with severe inflammation and several collections in the uterine wall. After hysterectomy, mechanical ventilation, temporary hemodialysis and broad-spectrum antibiotherapy, the patient recovered without neurological or systemic sequelae. Between the surgeries, the patient revealed a septic full abortion managed five days ago in another hospital in Brussels and a missed abortion diagnosed one week ago in a third hospital also in Brussels. The multiple organ failure, the pus in the right fallopian tube (observed during surgery), the Arias-Stella reactions and the trophoblastic tissue in the stoma of the right fallopian tube (histological results) made us conclude to a septic abortion of an intra-uterine pregnancy with likely contamination of an associated tubal pregnancy that was ignored at the time of the completed miscarriage of the intra-uterine pregnancy. Medical shopping (the patient went into three hospitals in one week) delayed the data gathering and worsened the management.
\end{abstract}

Conclusion: We should facilitate access to medical information between structures of health care system and, until this goal is achieved, we could inform the population about the risk of medical shopping.

Keywords: Missed abortion; Ectopic pregnancy; Tube mass; Multiple organ failure; Trophoblastic tissue

Abbreviations: HCG: Human Chorionic Gonadotropin; CRP: C-Reactive Protein; WBC: White Blood Cells; IV: Intravenous; CRL: Crown Rump Length; MSD: Mean Gestational Sac Diameter; ARDS: Acute Respiratory Distress Syndrome; DIC: Disseminated Intravascular Coagulation; CTScan: Computerized Tomography; IC: Intensive Care

\section{Background}

Spontaneous heterotopic pregnancy is estimated 1 case on 30 000 spontaneous pregnancies and 1 on 3900 pregnancies after Assisted Reproduction Techniques and ovulation induction [1]. In developed countries, spontaneous septic miscarriage is also rare $(0.7 / 100,000$ abortions, virtually identical for spontaneous abortion and induced abortion) and the prognosis depends often on the prompt removal of infected tissue [2].

\section{Case Presentation}

A 29 year old woman spontaneously pregnant was admitted in our hospital with acute abdomen and spotting without fever. Ultrasound assessment showed an empty bulky uterus, liquid in the Douglas and a right tube mass of $24 \times 17 \mathrm{~mm}$. Serum hCG (human chorionic gonadotropin) level was 1071IU/L, 
progesterone $0.76 \mu \mathrm{g} / \mathrm{L}$, CRP (C-reactive protein) $111 \mathrm{mg} / \mathrm{L}$ with $13.900 \mathrm{WBC} / \mathrm{mm}^{3}$. An urgent laparoscopy was performed for a suspected ectopic pregnancy. Ascites and a small amount of pus (salpingectomy) were identified, treated with peritoneal drainage and IV (intravenous) amoxicillin-clavulanic acid. The surgeon interrogated the patient wisely after the operation and important additional data came out: the patient was managed for a septic full intra-uterine abortion $(\mathrm{CRP}=310 \mathrm{mg} / \mathrm{dL})$ in another hospital in Brussels five days before our admission and, two days before that, a missed abortion was diagnosed (no heartbeat, CRL(crown rump length) $=12 \mathrm{~mm}$ and MSD (mean gestational sac diameter) $=29 \mathrm{~mm}$ in utero) with an ultrasound performed in a third hospital in Brussels also. After our laparoscopy, multiple organ failure (or multiple organ dysfunction syndrome $[3,4]$ occurred (ARDS (acute respiratory distress syndrome), DIC (disseminated intravascular coagulation), kidneys and liver insufficiencies) with hypothermia and biological severe inflammation (Figure 1).

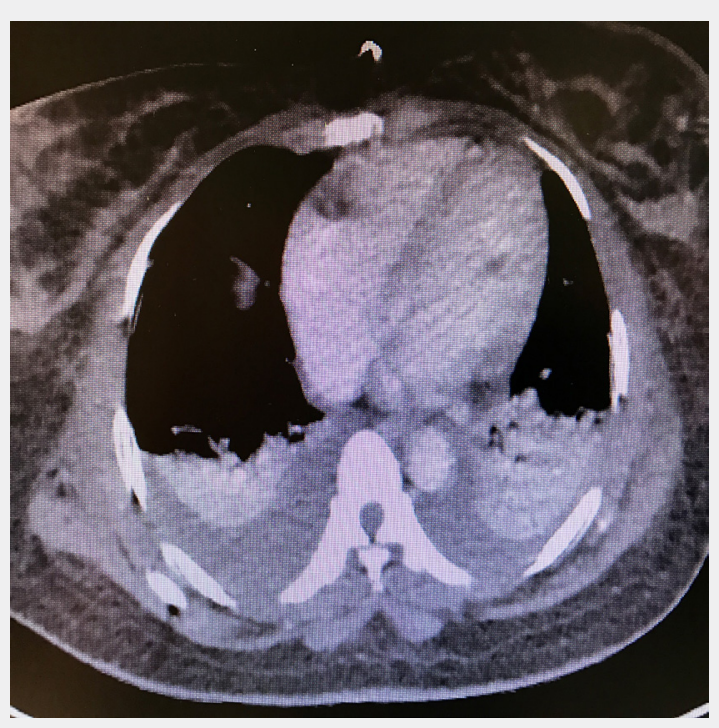

Figure 1: Thoracic CT: ARDS.

CT-scans (computerized tomography scans) showed several collections in the uterine wall $(7 \times 5 \mathrm{~cm})$, in the Douglas cavity (Figure 2) and in the right iliac fossa. With such clinical worsening, an indication of hysterectomy was discussed with the patient. After this surgical intervention and 15 days in IC (intensive care) unit for mechanical ventilation, temporary hemodialysis and broad-spectrum antibiotic therapy (doxycycline, ceftriaxone, clindamycine, vancomycine, Tazocin, en Imipenem), the patient recovered without neurological or systemic sequelae.

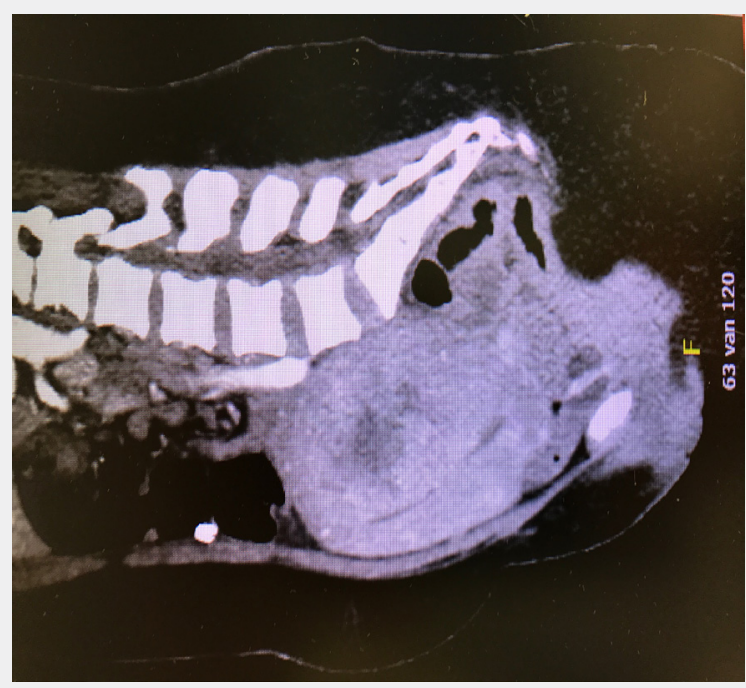

Figure 2: Abdo CT : collections in uterus. 
Histological examinations showed some trophoblastic tissue in the stroma of the right fallopian tube, Arias-Stella reactions and lymphocytes-neutrophils infiltration in the right fallopian tube (Figures 3), and, adenomyosis with ulcerative inflammation and thrombosis in the uterus. All cultures from blood, peritoneal, rectal, urine and vaginal samples were negative, but the patient was under amoxicillin-clavulanic acid or other antibiotics (doxycycline, ceftriaxone, clindamycine, vancomycine, Tazocin, en Imipenem) most of the time.

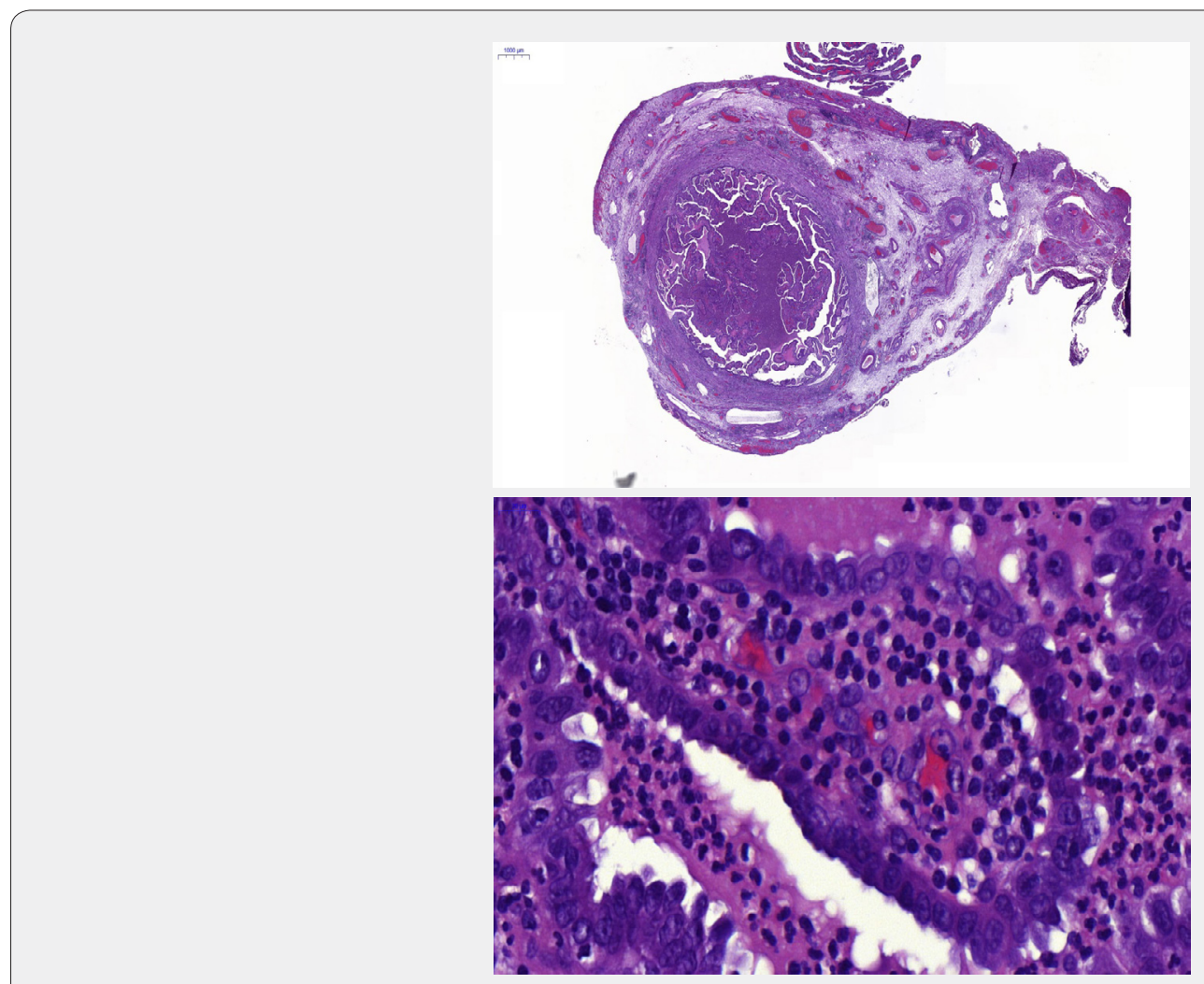

Figure 3: Histology: Tubal ectopic pregnancy with Arias-Stella reactions in the right tube's epithelium, and, infiltration with lymphocytes and neutrophils.

\section{Discussion and Conclusion}

Based on clinical presentation, biological inflammation and histological results combined with additional datas from other hospitals (missed abortion and CRP $=310 \mathrm{mg} / \mathrm{dL}$ ), the patient made a septic abortion of an intra-uterine pregnancy with likely contamination of an associated tubal pregnancy that was ignored at the time of the miscarriage of the intra-uterine pregnancy. The trophoblastic tissue of the right fallopian tube, like a residual trophoblastic tissue after an incomplete abortus, could offer a good culture medium for bacteria. Toxins from pathogen, or/ and excessive host response to pathogen inducing a complex network of molecular cascades, spread afterwards causing uterine thrombosis and multiple organ failure 4. A Clostridium sordellii could not be detected but can be suspected: such severe complications are reported with the same delay after septic abortus and without fever [2,5] Medical shopping delayed the data gathering and the diagnosis. This case illustrates well two problems: a) The severe complications of residual infected trophoblastic tissue

b) The frequent changes of health provider during a follow up, as we can often observe in Brussel, is a risky behavior.

We have probably observed the encounter of two rare entities: spontaneous heterotopic pregnancy and septic miscarriage. With medical shopping, the diagnosis was even trickier. We reiterate the already well-known adage: infected trophoblastic tissue should be prompt and completely removed, and always with antibiotic therapy to avoid or reduce septicemia. The access to medical informations between medical structures should be facilitated and the population should be more informed about the risk of "medical shopping", particularly until we find a way to improve the access of medical datas between medical structures. It is not only an economical problem but also and mostly a risk of delayed diagnosis. 


\section{Consent Section}

Written informed consent was obtained from the patient for publication of this case report and any accompanying images. A copy of the written consent is available for review by the Editorin-Chief of this journal.

\section{Declarations}

a) Ethical Approval and Consent to participate: not applicable.

b) Consent for publication: The patient consents to the anonymous publication of her data.

c) Availability of supporting data: all medical data are available in UZ Brussel.

d) Competing interests: We have no conflict of interest or funding for this work.

e) Funding: not applicable. f) Authors' contributions: All authors contributed to the writing and the collections of data.

g) Acknowledgements: not applicable.

Authors' information (Optional).

\section{References}

1. Chadee A, Rezai S, Kirby C, Chadwick E, Gottimukkala S, et al. (2016) Spontaneous heterotopic pregnancy: Dual case report and review of literature. Case Rep Obstet Gynecol.

2. Eschenbach DA (2015) Treating spontaneous and induced septic abortions. Clinical Expert Series. Obstetrics \& Gynecology, 125(5): 1042-1048.

3. Bone RC, Balk RA, Cerra FB, Dellinger RP, Fein AM, et al. (1992) Definitions for sepsis and organ failure and guidelines for the use of innovative therapies in sepsis Crit Care Med. Chest 101(6): 1644-1655.

4. Gustot T (2011) Multiple organ failure in sepsis: prognosis and role of systemic inflammatory response. Curr Opin Crit Care 17(2):153-159.

5. Fischer M, Bhatnager J, Guarner J, Reagan S, Hackeret JK, et al. (2005) Fatal Toxic Shock Syndrome Associated with Clostridium sordellii after Medical Abortion. NEJM 353(22): 2352-2360.

\section{Your next submission with Juniper Publishers will reach you the below assets}

- Quality Editorial service

- Swift Peer Review

- Reprints availability

- E-prints Service

- Manuscript Podcast for convenient understanding

- Global attainment for your research

- Manuscript accessibility in different formats

( Pdf, E-pub, Full Tsext, Audio)

- Unceasing customer service

Track the below URL for one-step submission https://juniperpublishers.com/online-submission.php 